\title{
An Inexpensive Device for Multiple Depth Sampling of Groundwater Quality in Cohesionless Aquifers ${ }^{1}$
}

Wendy D. Graham²

In recent years many new devices have become available for groundwater-quality monitoring. These devices provide various means of access to the groundwater zone for acquisition of groundwater samples for chemical analysis. When assessing the options that exist for groundwater-quality monitoring at a particular site, there are an appreciable number of monitoring devices to consider. The selection of the appropriate device will depend on hydrogeological conditions at the monitoring site, the availability and the terrain accessibility of drilling equipment, and the construction materials needed to prevent the adsorption of contaminants onto the monitoring devices or release of contaminants from the devices. The purpose of this publication is to describe methods for the construction and installation of an inexpensive device for sampling groundwater quality in sandy, cohesionless aquifers.

\section{Depth-integrated Versus Depth-specific Sampling}

Early in the selection process for groundwater-quality monitoring, it is necessary to determine whether depth-integrated or depth-specific samples are desired. A depth-integrated sample is one that is obtained when water is pumped from a well that has a long screen or from a well with an open borehole. As pumping occurs water can flow into the well or open borehole from various depth levels rather than from an isolated depth level. A depth-specific sample is one that is obtained in a specific narrow depth interval from an isolated zone in a well or borehole.

Depth-integrated and depth-specific sampling are illustrated schematically in Figure 1.

Depth-integrated sampling can identify the presence of a contaminant in the groundwater system but cannot determine the actual depth or in situ concentration of the contaminated zone. The concentrations obtained from a depth-integrated sample are normally dependent on the length of the screened interval, the depth of the pump intake, and the rate or time-period of pumping. Even under very controlled conditions of pumping and sampling, it is generally not possible to deduce the concentration distribution in the formation. Therefore, depthintegrated sampling is not usually the preferred approach for detailed groundwater-quality

1. This document is CIR943, one of a series of the Agricultural and Biological Engineering Department, Florida Cooperative Extension Service, Institute of Food and Agricultural Sciences, University of Florida. Original publication date May 1991. Reviewed July 2002. Visit the EDIS Web Site at http://edis.ifas.ufl.edu.

2. Wendy D. Graham, assistant professor, Department of Agricultural and Biological Engineering Department, Cooperative Extension Service, Institute of Food and Agricultural Sciences, University of Florida, Gainesville, 32611.

The Institute of Food and Agricultural Sciences (IFAS) is an Equal Employment Opportunity - Affirmative Action Employer authorized to provide research, educational information and other services only to individuals and institutions that function without regard to race, creed, color, religion, age, disability, sex, sexual orientation, marital status, national origin, political opinions or affiliations. For information on obtaining other extension publications, contact your county Cooperative Extension Service office. Florida Cooperative Extension Service / Institute of Food and Agricultural Sciences / University of Florida / Larry R. Arrington, Interim Dean 
monitoring. However, the depth-integrated approach may be appropriate in situations where one simply desires, with minimum drilling effort, to determine whether or not contamination exists at a particular monitoring site. It is often the most appropriate technique for evaluations of water quality for public water supply wells.

Depth profiles are usually an important aspect of detailed groundwater-quality investigations since contaminant concentrations in bedded deposits can vary markedly in the vertical direction and, in some situations, the entire zone of contamination may occupy only a small part of the total aquifer thickness. This zone could go undetected, or could mistakenly be assumed to represent conditions over the entire aquifer depth, if vertical profiles were not available. When depth-specific sampling is performed, the water sample is drawn from a narrow interval in the borehole in a manner that minimizes mixing of water from different depth zones. If this is accomplished, the concentrations in the sample at the moment of sampling will represent the concentrations in the formation at the depth of sampling. When this sampling approach is used, it is usually necessary to do depth-specific sampling at several depths at each sampling location in order to determine the overall conditions of groundwater quality at the location.

\section{Approaches for Depth-specific Sampling}

There are three designs that can be used for permanent depth-specific sampling systems (See Figure 2). These are (1) multiple-borehole piezometer nests; (2) multiple-level, single borehole packer sampling; and (3) multiple-level, single borehole piezometers.

A multiple-borehole piezometer nest consists of two or more boreholes at the same site, with each hole extending to a different depth, and each hole containing a single small diameter pipe screened or slotted over a short interval and capped at the bottom. Until recently this was the only depth-specific approach that was commonly used for groundwater-quality monitoring at various levels. New methods have recently been developed primarily to diminish the drilling costs associated with the establishment of multilevel monitoring networks.
Multiple-level packer sampling refers to sampling from different levels in a long screened interval or in an open borehole. Each interval is temporarily isolated by means of inflatable packers and the sample is drawn from the zone between the packers. After an interval is sampled, the packers are deflated and the packer assembly is raised or lowered to a different interval where the packers are reinflated so that another sample can be taken. By repeating this procedure, samples can be obtained from many depths in a single hole. Multi-level packer sampling can be a relatively inexpensive approach to groundwater-quality monitoring but it has a severe liability. Between sampling times the borehole provides an open pathway for movement of groundwater from one depth level to another. If groundwater moves from one depth zone to another via the open borehole or screen during the periods between sampling times, it is difficult or impossible to obtain representative depth-specific water quality samples during temporary episodes of packer inflation and pumping. This publication presents a design for an inexpensive multiple-level, single borehole piezometer which prevents vertical short-circuiting during periods of non-sampling.

\section{Design Considerations for the Multi-level Sampler}

The multi-level sampling device described in this publication was developed by researchers at the University of Waterloo, Waterloo, Ontario, Canada (Cherry et al., 1983) and has subsequently been used for many research and commercial applications (MacKay et al., 1986; Garabedian, 1987; TVA, 1988; Hyman, 1990). A schematic of this device is shown in Figure 3. In general, the device consists of an outer casing (usually PVC) with small port holes drilled into it. A bundle of small-diameter collection tubes (either metal, polypropylene, or teflon) extend from the ground surface down the inside of the casing. Each of the tubes is attached to a sampling port which protrudes slightly from the casing pipe. Screening materials are used to cover each sampling port to prevent soil from entering and clogging the tubing.

A summary of the criteria which should be considered in the design and construction of a multi-level sampler (MLS) is presented below. In 
addition to cost considerations, the chemical and physical properties of the soil, groundwater, and contaminant(s) of interest must be carefully considered before an MLS is selected as the optimal groundwater- monitoring device for any particular site.

\section{Soil Collapsibility}

Soil collapsibility is of primary concern when using the MLS. Where the soil is unable to collapse tightly around the MLS (i.e. in clayey deposits), groundwater may move upward or downward along the borehole zone, and thus samples withdrawn at a particular depth will not be representative of what is actually occurring at that depth in the aquifer. Unconsolidated cohesionless soils are required for accurate implementation of MLS.

\section{Depth of Water Table below Ground Surface}

The MLS device described in this publication requires a vacuum pump to draw groundwater through the subsurface sampling ports to the ground surface. Since the theoretical suction lift of a vacuum pump is approximately 33 feet ( 1 atmosphere), the MLS described in this publication cannot be used at sites where the water table is more than 25 to 28 feet below ground surface.

\section{Contaminant Considerations}

The materials selected for constructing the MLS will depend on the contaminants being sampled for. If organic constituents (such as pesticides) which are capable of sorbing onto plastics are being sampled the inner tubing, fittings and screening should be constructed of metal, glass, or teflon. In addition no glue, tape or caulk should be used in the construction procedure since these substances may leach organic compounds into the sample water.

If inorganic constituents such as nitrate, phosphate or chlorides are being sampled for, polyethylene tubing and fittings, and nylon screening material are appropriate. Glue, tape and/or caulk may be used since compounds leached from these materials should not affect the inorganic ion analysis.

\section{Construction Methods for the Multi-level Sampler}

Figure 4 shows a detailed schematic of the construction methods and materials required for a MLS designed to sample organic constituents (Hyman, 1990). The sampling ports consist of brass elbows which are held to the PVC casing pipe by thin brass nuts. The outer threaded ends of the elbows can be sanded down, if necessary, to prevent the edges from damaging the screening materials. The inner threaded ends are connected to aluminum tubing which extends to the surface inside the PVC casing pipe. The aluminum tubing is $60 / 61$ grade, $3 / 16$ diameter with an 0.035 inch wall, and is connected with brass unions where necessary. The PVC is threaded, Schedule 40, and purchased in ten-foot sections. Size 36 stainless steel hose clamps are used to fix the screening materials over the sampling port.

As a first step in constructing the multi-level organic sampling device, all interior and exterior metal surfaces should be rinsed with acetone and then distilled water to clean the metal of possible cutting oils. Holes are drilled into the 10-foot lengths of PVC casing pipe where each sampling port will be, just large enough to allow the threaded end of the brass elbow to fall through. The elbows are each fastened to the appropriate length of aluminum tubing depending on the depth of the sampling port they are to be attached to. The elbows are put into the holes by laying the PVC pipe horizontally, hole down, and sliding the aluminum tubing elbow-first into the pipe, threaded end down, until the threaded end of the elbow falls into the hole. The nut is then fastened on the outside of the PVC pipe, forming the sample port. As each port is installed, its order along the sampler is labeled to keep track of its depth during construction. The screening materials are placed over each port and fastened above and below with stainless steel hose clamps. The materials required to construct a 20-foot MLS with 10 sampling ports for organic constituent sampling cost approximately $\$ 160$ (1990 dollars), and a single device takes approximately 2 to 3 man-hours to construct.

Figure 5 shows a detailed schematic of the construction methods and materials required for a 
MLS designed to sample inorganic constituents (Garabedian, 1987). The Schedule 40 PVC is purchased in ten-foot sections and connected where necessary with glued couplings and fittings. The 1/4-inch outside diameter polyethylene tubing is purchased in 100-foot sections. Stainless steel wire is used to attach the nylon screening material (210-mesh nylon cloth or women's nylon pantyhose material) over the sampling port, and to attach the sampling port to the PVC casing pipe.

Holes are drilled into the 10-foot lengths of PVC casing pipe just above the desired depth. The holes should be angled down, and should be just large enough for the polypropylene tubing to fit through. The polyethylene tubing is fed through the hole and up to the top of the casing pipe. Two inches of tubing should be left sticking out of the sampling port and cut at an angle. A double thickness of nylon screening material is wrapped over the polyethylene tube and bound with stainless steel wire to attach it to the tube. The sampling port is then fastened to the PVC casing with stainless steel wire. As each port is installed, its order along the sampler is labeled to keep track of its depth during construction. It is very important to maintain the labels on each tube so that after installation it is known which tube is connected to which port under the ground. Labels must be written and applied in a manner that is permanent. A coded colored tape scheme, with a different color representing each depth, is recommended. The materials required to construct a 20-foot MLS with 10 sampling ports for inorganic constituent sampling cost approximately $\$ 40.00$ (1990 dollars), and a single device takes approximately 1 to 2 man-hours to construct.

\section{Installation Methods for the Multi-level Sampler}

Multi-level samplers (MLS) which are to be set at depths greater than 10 feet below ground surface are most easily installed by means of a truck- or trailer-mounted drill rig equipped with continuous flight hollow stem augers. At each sampling location the string of augers is advanced to the desired depth and the MLS is lowered down the hollow stem of the augers to the bottom of the hole. As the augers are gradually backed out of the hole the aquifer sands should close in tightly around the MLS below the water table. This occurs because the sand has little or no cohesion and because of the large pressure difference between the aquifer and the empty augers. In some cases movement of the sand into the borehole as the augers are withdrawn may be so rapid that sand flows upward into the annulus between the augers and the MLS. This can cause the MLS to jam in the augers, and in some cases may require that the MLS be removed with the augers. In this case a new bore-hole must be drilled to install the MLS.

Problems associated with the influx of sand into the auger annulus can be avoided if the auger hollow stem is filled with water immediately prior to withdrawing the augers. The water pressure in the hollow stem of the augers thus prevents sand from entering the auger stem. This method has the disadvantage of causing foreign water to be introduced into the borehole zone around the MLS which may affect the analysis of some constituents in the groundwater. This water can be removed by pumping the device extensively or allowing several weeks of flow time before using the device for groundwater-quality monitoring.

An alternative way to prevent jamming of sand in the augers is to seal the bottom of the hollow stem of the lead auger with a rubber or wood stopper before drilling is begun. After the hole is drilled and the desired depth is attained, the MLS is lowered down the hole and used to tap the stopper out of the end of the auger. After the stopper has been removed the augers should be backed out of the hole as quickly as possible in order to prevent jamming.

If the MLS is being set at a depth of less than ten feet it can be installed manually. Using this method a 4-inch PVC casing is installed by hand augering the borehole to 6 or 8 feet, then driving the casing to the desired depth using a hammer or other portable impact device. Once the desired depth has been attained the MLS is lowered into the casing. The casing may then be removed using jacks or a tripod winch. Although this method is labor intensive, it is inexpensive and can be used in areas inaccessible to drill rigs. Hand augering/ hammering is preferable to jetting the casing in with water because it introduces no foreign water into the borehole. 
After the MLS has been installed, and the aquifer material has collapsed so tightly around the MLS that it cannot be moved back and forth by hand, the open area around the MLS above the water table should be backfilled with the soil brought up by the auger. (Note-it may take up to 24 hours for the aquifer material to collapse tightly around the MLS). If necessary, protective well covers with lockable lids may then be cemented into the ground over each sampler.

\section{Sampling Methods for the Multi-level Sampler}

Samples may be obtained by applying suction to each sampling tube using a peristaltic vacuum pump. Initially, flow rates are often low because of clogging of the sample point by fine particles. The flow rate can usually be increased by alternate episodes of back-flushing and pumping (except in cases where the sample point is situated in a layer of clay or slit, or where the port's screening material has been destroyed during the installation process). After each slow-yielding sample-point has been "developed" in this manner, the MLS should be allowed to set for one to two weeks so that the groundwater can redevelop equilibrium conditions in the disturbed areas around the MLS.

After development, the entire ensemble of tubes in the MLS should be sampled simultaneously, if possible, so that a horizontal flow pattern is induced toward the MLS. When the MLS ports are pumped simultaneously during sampling, the sampling area will be from halfway between the sampled port and the ports above and below it. The diagram in Figure 6 shows the approximate flow patterns to a MLS during multi-port sampling. Multi-head peristaltic pumps, such as those manufactured for laboratory or medical applications, are ideal for this purpose. Because of the small diameter tubing, the MLS generally yields water at a few liters per minute or less. The two main issues pertaining to time of pumpage prior to sampling relate to the pumpage volume necessary to remove all of the standing water from the tubing and the pumpage volume necessary to draw water from a representative volume around the MLS port. It is desirable to remove the standing water from the piezometer prior to sampling so that the water taken for the sample is free from the effects of chemical changes that may have occurred while the standing water resided in a stagnant state in the tubing. Once the standing water has been removed it is only necessary to pump an additional volume sufficient to obtain a representative sampling of the formation water. In other words, the groundwater taken for the sample should be pumped from a radius equal to or greater than the extreme outer radius of the augered borehole.

It should be kept in mind that pumping of the sampling tubes continually draws water toward the piezometer from increasingly large distances in the formation. Continued pumping causes continued disturbance of the flow domain in the vicinity of the MLS. Whether or not a short period of disturbance or a long period of disturbance produces a more representative or less representative sample is still an open question. Probably the only issue on which there is some agreement with respect to pumping rate and duration prior to sampling pertains to consistency. It is desirable to apply generally similar rates and duration on each sampling occasion at a particular MLS. If the hydrogeologic conditions permit, consistency from MLS to MLS is also desirable.

\section{Summary}

Methods for the design, construction and installation of an inexpensive device for multi-level sampling of groundwater quality in shallow, sandy, cohesionless aquifers are presented in this publication. A 20 -foot-long device with ten ports for sampling inorganic constituents costs approximately $\$ 40$ (1990 U.S. dollars) and takes approximately 1 to 2 man-hours to construct. A similar device for sampling organic constituents costs approximately $\$ 160$ (1990 U. S. dollars) and takes approximately 2 to 3 man-hours to construct. Either device may be installed to depths of 10 feet or less by hand-augering techniques, or to larger depths using a truck-mounted drill rig equipped with continuous flight hollow-stem augers.

Multi-level samplers take samples from many small, discrete zones in the aquifer and therefore are capable of providing accurate vertical contaminant 
concentration profiles. Samples from conventional monitoring wells on the other hand provide only an average of the contaminant concentration in the aquifer over the length of the well screen. Depth profiles are often considered a necessary aspect of groundwater-quality monitoring because contaminant concentrations can vary markedly in the vertical direction and, in some situations, the entire zone of contamination may occupy only a small part of the total aquifer thickness. This zone could go undetected, or could mistakenly be assumed to represent conditions over the entire aquifer depth, if detailed vertical profiles were not available. In general, with the effort it takes to drill one hole, more information may be obtained by installing a multi-level sampler than a conventional monitoring well.

\section{References}

Cherry, J. A., R.W. Gillham, E.G. Anderson, and P.E. Johnson, (1983). Migration of Contaminants in Groundwater at a Landfill: A Case Study, 2. Groundwater Monitoring Devices. Journal of Hydrology, 63, 31-49.

Garabedian, S. P.,(1987). Large-Scale Dispersive Transport in Aquifers: Field Experiments and Reactive Transport Theory. Ph. D. Dissertation, Massachusetts Institute of Technology, Cambridge, MA, 290pp.

Hyman, J.A.,(1990). Groundwater Monitoring in Three Dimensions using the Multi-Level Sampler. M.S. Thesis, Massachusetts Institute of Technology, Cambridge, MA, 121pp.

MacKay, D.M., D.L. Freyberg, and P.V. Roberts, (1986). A Natural Gradient Experiment on Solute Transport in a Sand Aquifer, 1. Approach and Overview of Plume Movement. Water Resources Research, 22(13), 2017-2029.

Tennessee Valley Authority, (1988). Evaluation of Tracer Sampling Devices for the Macrodispersion Experiment. Electric Power Research Institute Technical Report No. EA-5816. 